\title{
Design and Development of a Helmholtz Pair System for Production of a Low-Magnetic Field of up to $7.5 \mathrm{mT}$
}

\author{
Yenal Gokpek ${ }^{1+} \mathbb{D}$, Ozgun Boray Yurdakos ${ }^{2} \mathbb{D}$, Ozkan Doganay $^{3}$ (D) \\ ${ }^{1 *}$ Ege University, Fundamental Oncology Department, Institute of Health Sciences, 35100, Izmir, Turkey. (e-mail: yenalgokpek@ gmail.com). \\ ${ }^{2}$ Ege University, Fundamental Oncology Department, Institute of Health Sciences, 35100, Izmir, Turkey. (e-mail: obyurdakos@ gmail.com). \\ ${ }^{3}$ Ege University, Fundamental Oncology Department, Institute of Health Sciences, 35100, Izmir, Turkey. (e-mail: ozkan.doganay@ege.edu.tr)
}

\section{ARTICLE INFO}

Received: Oct., 06. 2021

Revised: Nov., 21. 2021

Accepted: Nov., 23. 2021

Keywords:

Helmholtz Coil

Magnetic Field

Spin Exchange Optical Pumping

Corresponding author: O. Doganay

ISSN: 2536-5010 | e-ISSN: 2536-5134

DOI: https://doi.org/10.17694/ejt.991890

\section{ABSTRACT}

In this study, the design, numerical modelling, and construction of various Helmholtz pair coil systems were investigated to produce a homogeneous magnetic field. The magnetic field was simulated using three different Helmholtz coil systems including 2-coil, 3-coil, and 4-coil combinations in order to optimize the field homogeneity and strength over a region of interest that consists of a cylindrical geometry with a height of $700 \mathrm{~mm}$ and a diameter of $90 \mathrm{~mm}$. The simulated magnetic field created by the 4-coil system was found to be more homogenous than 3-coil and 2-coil systems over the region of interest. The 4-coil system was constructed and tested by using two commercially available low-power ( $\mathrm{P}=600$ W) DC power supplies. For further optimization, the number of turns and diameter of coil elements were simulated. The optimum number of turns and elements were determined to be 140 and 80 turns for the outer pair and inner pair of the 4-coil system, respectively. Finally, the produced magnetic field strength was measured using a hand-held gaussmeter and compared to the simulated magnetic field. We found that the system can produce a magnetic field of $\mathrm{B}=7.5047 \pm 0.0562 \mathrm{mT}$, and the correlation between simulated and measured magnetic fields were calculated to be $\mathrm{R}=0.9824$ with $(\mathrm{p}<0.001)$ suggesting a statistically significant agreement.

\section{INTRODUCTION}

Recent improvements in the field of magnetic resonance imaging (MRI) have shown that relatively low-magnetic fields lower than 0.5 Tesla can be used to achieve reasonable image quality compared to the clinical MR scanners that employ magnetic field strength stronger than 1 Tesla $[1,2]$. Compared to the conventional MR systems, low-field systems promise to provide more effective field homogeneity with the advantage of easy installation and cost-effective maintenance [3]. Additionally, the novel hyperpolarized MRI techniques including Xenon-129, Helium-3, and Carbon-13 renewed interest in the design and optimization of the low-magnetic field systems [4-10] with the advantage of reduced magnetic field strength in the order of 2-10 $\mathrm{mT}[6,11-14]$. One other relevant application of low-strength magnetic field is the spinexchange optical pumping (SEOP) technique that is used to polarize Xenon-129 gas [15-18].

Recent studies have investigated the feasibility of low-field systems for imaging organs including the brain, lungs, heart, and musculoskeletal [19-22]. Additionally, custom-built magnet systems and detectors were widely used in nuclear magnetic resonance (NMR) systems for producing uniform magnetic fields in medical, biological and chemical analysis applications [23-27]. While these systems generate relatively uniform magnetic fields in small volumes between 100$200 \mathrm{~mm}$, they are not capable of relatively larger volumes. Although Helmholtz coils were very effective for generating uniform magnetic fields over larger volumes, the classical twocoil systems require a distance between the coils that is equal to the coil radius making it difficult to implement into the lowfield NMR and MRI systems. In this respect, Helmholtz systems that consist of multi-coil pairs would offer further improvements in the design and construction of the low-field systems.

In this study, a theoretical optimization and design of a lowfield Helmholtz coil system have been investigated to produce a magnetic field that takes up less space than the classical Helmholtz coil systems for the use of SEOP and the low-field animal MR imaging systems.

\section{MATERIALS AND METHODS}

\subsection{Numerical Simulations:}

Three different Helmholtz coil systems were simulated for investigating the magnetic field homogeneity: (i) the first 
designed Helmholtz coil system assembled of four coil elements (i.e. 4-coil as shown in Figure 1), (ii) the second system contained three coil elements (i.e. 3 -coil), and (iii) the third system contained two elements (i.e. 2-coil). Then, for the best number of elements, the winding numbers were simulated to further optimize the uniformity of the magnetic field.

Magnetic fields generated by each coil system (2-coil, 3coil, 4-coil) were calculated using MATLAB with a fixed mesh size of $2 \mathrm{~mm}$ and solving the general magnetic vector potential equations [28]. The magnetic field vector for a single winding was calculated by the superposition principle as well as the net magnetic field [29].

Since the DC power supplies could create $600 \mathrm{~W}$ power, the magnetic field was simulated for an electric current of 19.5A. The cross-sections of the simulated magnetic fields were compared between three different coil systems for determining the most homogenous magnetic field.

To optimize winding numbers, magnetic field variations were calculated by the ratio of standard deviation to mean magnetic field strength within the ROI as shown in Figure 1 as the red cylinder. The ROI was chosen to be $700 \mathrm{~mm}$ long, 90 $\mathrm{mm}$ wide, and centered to the middle of the coil systems for investigating the feasibility of this system in the field of small animal imaging or a SEOP system.

The number of windings was varied from 1 to 200 turns in 1 turn increments for elements I-IV and elements I-III while keeping the positions and electric currents constant.

\subsection{System Configurations:}

Each coil element was numbered from top to bottom as shown in Figure 1a and powered by a DC power supply (TTTECHNIC, KXN-3020D) in constant current mode. I-element and IV-element in Figure 1a were connected in series to a power supply, as well as II-element and III-element to an identical power supply for crude shimming as previously explained by Mair et al. [7]. Physical parameters of coil systems including electric current, windings, coil element positions, and diameters were given in Table 1. Coil elements were constructed by hand-wounding an enamel-coated copper wire with a diameter of $3 \mathrm{~mm}$ and length of $900 \mathrm{~m}$ onto custommade aluminum spools as shown in Figure 2. The frame that holds the coils in place was constructed with $45 \times 45 \mathrm{~mm}$ aluminum sigma profiles. The constructed 4-coil element Helmholtz system is shown in Figure 2.
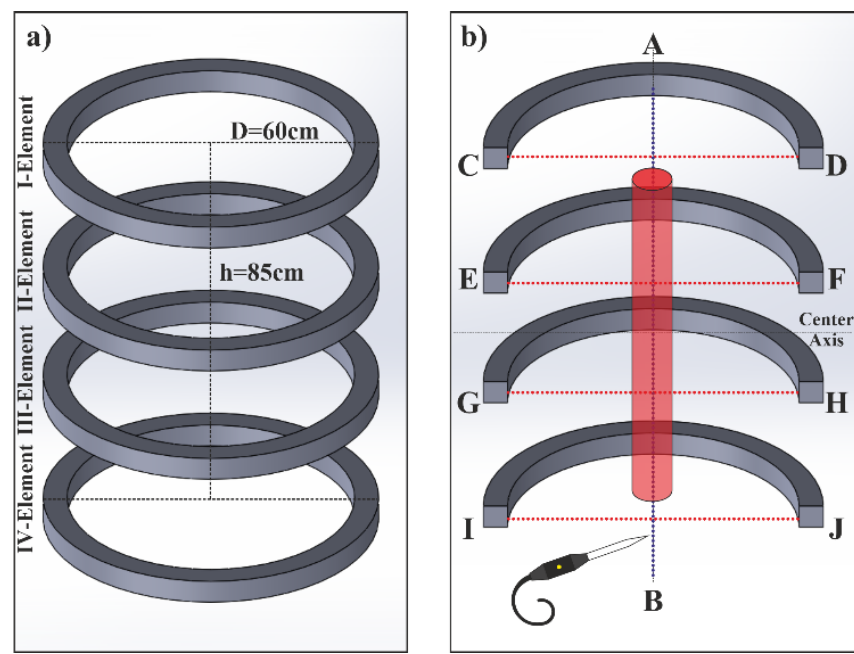

Figure 1. 3D representation (a) and measurement points (b) of the simulated and constructed system (ROI shown in red).
TABLE I

PARAMETERS OF COIL SYSTEMS

\begin{tabular}{cccccc}
\hline \hline & COIL & $\begin{array}{c}\text { ELECTRIC } \\
\text { CURRENTS } \\
\text { ELEMENTS }\end{array}$ & $\begin{array}{c}\text { TURNS } \\
(\mathrm{N})\end{array}$ & $\begin{array}{c}\text { DISTANCE } \\
\text { FENTER } \\
\text { AXIS } \\
(\mathrm{MM})\end{array}$ & $\begin{array}{c}\text { COIL } \\
\text { DIAMET } \\
\text { ER (MM) }\end{array}$ \\
\hline $\begin{array}{c}\text { 2-COIL } \\
\text { SYSTEM }\end{array}$ & I AND II & 18.3 & 140 & 260 & 600 \\
\hline $\begin{array}{c}\text { 3-COIL } \\
\text { SYSTEM }\end{array}$ & I AND III & 18.3 & 140 & 360 & 600 \\
\hline 4-COIL & I AND IV & 18.3 & 140 & 425 & 600 \\
SYSTEM & II AND III & 19.5 & 80 & 127 & 600 \\
\hline \hline
\end{tabular}

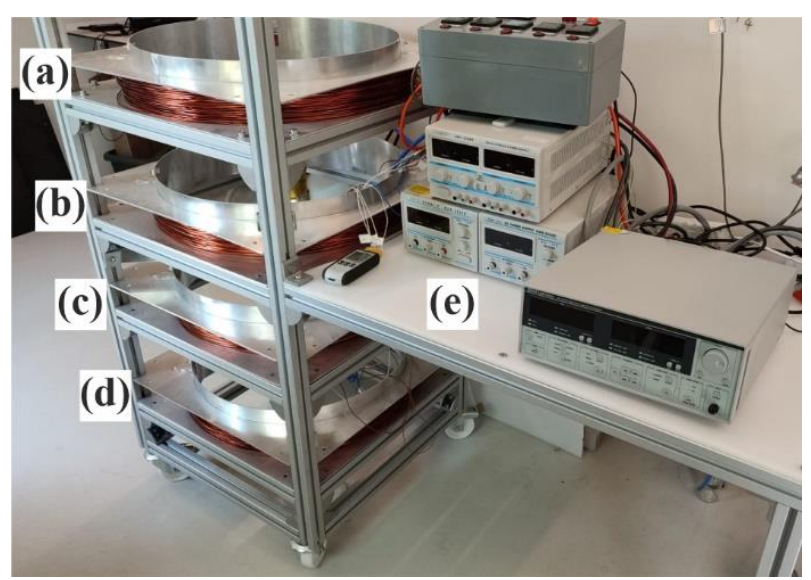

Figure 2. Constructed system: (a) I-element, (b) II-element, (c) III-element, (d) IV-element, and (e) power supplies.

\subsection{Magnetic Field Measurements}

The generated magnetic field along the coil axis and radii were measured horizontally and vertically between points A-B, C-D, E-F, G-H, I-J using a gaussmeter probe with a step size of $10 \mathrm{~mm}$ as shown in Figure 1b. The gaussmeter probe (PCEMFM 3000) was capable of measuring magnetic field strength values up to $300 \mathrm{mT}$ with a resolution of $0.025 \mathrm{mT}$. For validating the simulation results and model, the correlation between the measured magnetic field strength and simulation results were compared using Pearson's correlation, including the $\mathrm{p}$-values.

To investigate the linearity between applied electric current and produced magnetic field, the 4-coil system was driven by varying electric current values from $1 \mathrm{~A}$ to $19 \mathrm{~A}$ while keeping the ratio of electric currents between the power sources constant.

\section{RESULTS}

For optimization of the number of windings, the simulated magnetic field homogeneity concerning coil elements I- IV and II-III are shown in Figure 3. The values of 140 turns for I- and IV-elements and 80 turns for II- and III-elements, which are shown in Figure 3 provided the most homogeneous magnetic field distribution. More turns would increase the resistance value of the coils, which in turn increases the value of the required voltage for supplying desired electric currents. The constructed I-IV-elements had approximately $1.39 \Omega$ resistance in series and II- III-elements had approximately $0.78 \Omega$ 
resistance in series at room temperature. This resistance resulted in a temperature increase of $58.9^{\circ} \mathrm{C}$ in I- and IVelements and $50.1^{\circ} \mathrm{C}$ in II and III elements which did not affect the constant current mode performance of the power supplies.

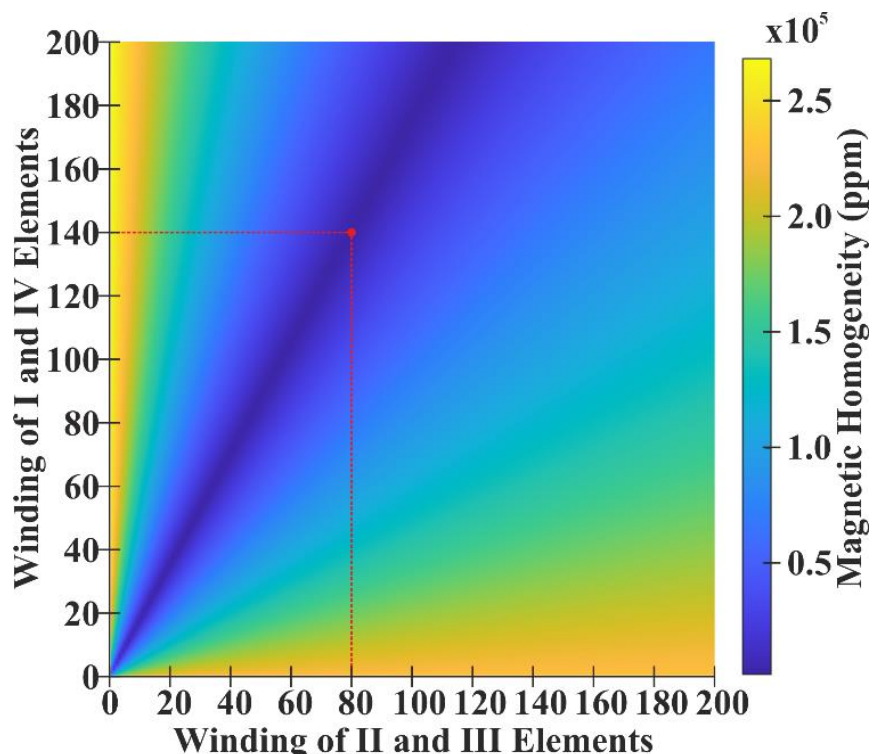

Figure 3. Magnetic field homogeneity values (in ppm) depending on winding numbers of elements are shown.

The linearity of the produced magnetic field strength with the applied current is shown in Figure 4.

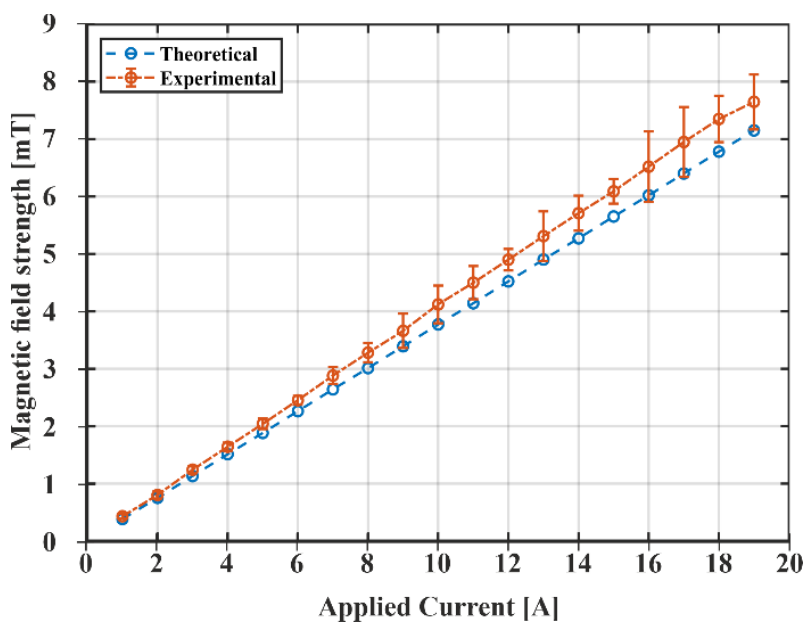

Figure 4. Simulated (blue) and measured (orange) magnetic field values at the center of the 4-coil system as a function of electric current.

The simulated magnetic field cross-sections are shown in Figure 5 for the 2-coil, 3-coil, and 4-coil Helmholtz systems with the simulation parameters that are given in Table 1 . The simulated magnetic fields within the ROI were summarized in Table 2. The standard deviation was lowest for the 4-coil system, suggesting that the produced magnetic field was more homogeneous than other coil setups. In a closer inspection, the generated magnetic field was very homogenous over the ROI with the magnetic field variations of less than $1 \%$.

Figure 6.a shows the simulated and measured magnetic field vertically from point A to B in Figure 2.b. Particularly, the magnetic field variations were less than $0.056 \mathrm{mT}$ at ROI between points $-350 \mathrm{~mm}$ and $+350 \mathrm{~mm}$ showing that the system produces a very uniform magnetic field. The simulated line profile of the magnetic field from A to B (Figure 6a) was also compared to the experimental measurements. The measured magnetic field strength values were slightly greater than the simulated values of $5.6 \%$ suggesting a reasonable agreement between the simulated and measured magnetic fields.

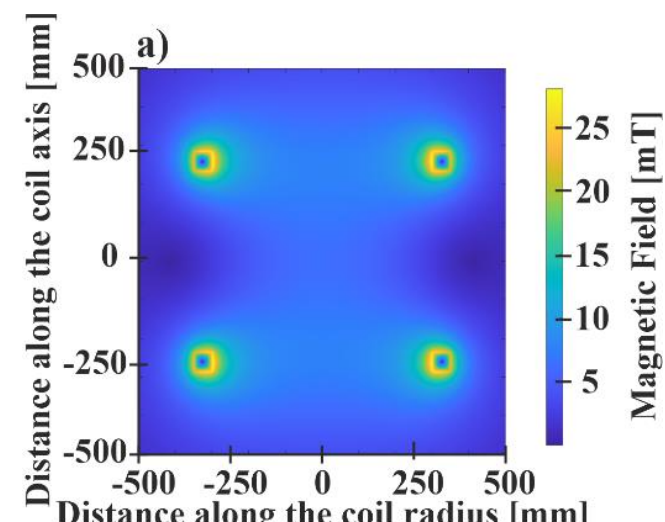

Distance along the coil radius $[\mathrm{mm}]$
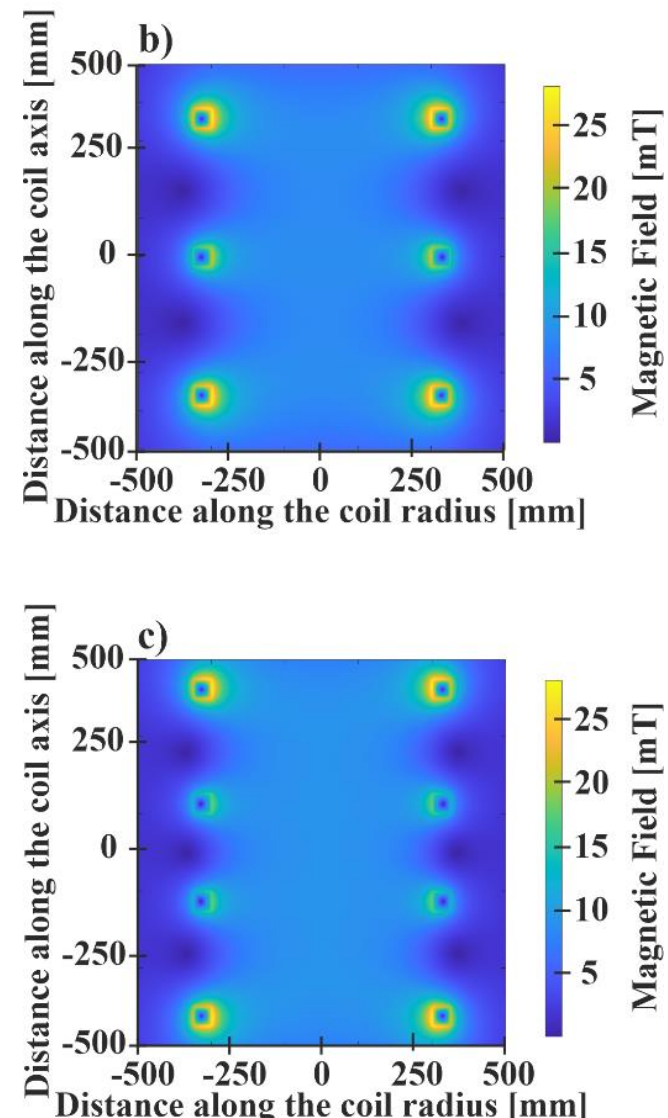

Figure 5. Theoretical calculation of magnetic field strength (in mT) for 2-coil (a), 3-coil (b), and 4-coil (c).

TABLE II

MAGNETIC FIELD STRENGTH VALUES GENERATED BY COIL SYSTEMS FROM A TO B WITHIN THE ROI

\begin{tabular}{|c|c|c|c|c|}
\hline & $\begin{array}{c}\text { HELMHOLTZ } \\
\text { SYSTEMS }\end{array}$ & $\begin{array}{c}\text { MEAN } \\
\text { MAGNETIC } \\
\text { FIELD } \\
\text { STRENGTH (MT) } \\
\end{array}$ & $\begin{array}{c}\text { STANDARD } \\
\text { DEVIATION } \\
(\mathrm{MT})\end{array}$ & $\begin{array}{c}\text { STANDARD } \\
\text { DEVIATION } \\
(\mathrm{PPM})\end{array}$ \\
\hline zo & 2-COIL & 5.2818 & 0.3430 & 64932 \\
\hline 岕 & 3-COIL & 6.5218 & 0.0617 & 9465 \\
\hline $\bar{s}$ & 4-COIL & 7.1045 & 0.0099 & 1395 \\
\hline 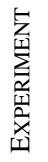 & 4-COIL & 7.5047 & 0.0562 & 7485 \\
\hline
\end{tabular}


a)

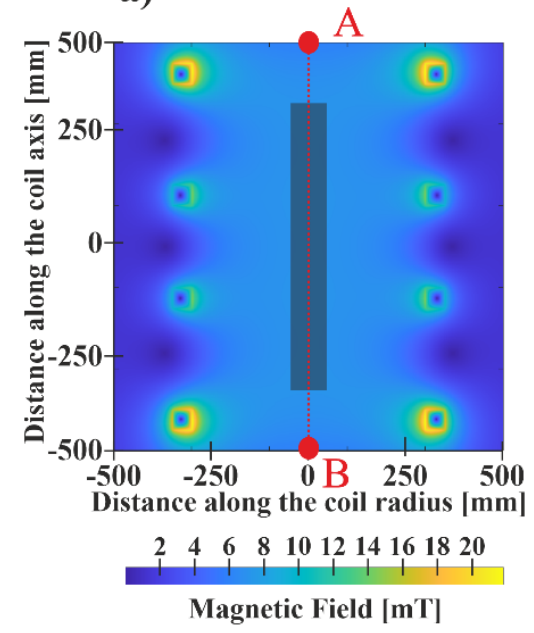

b)

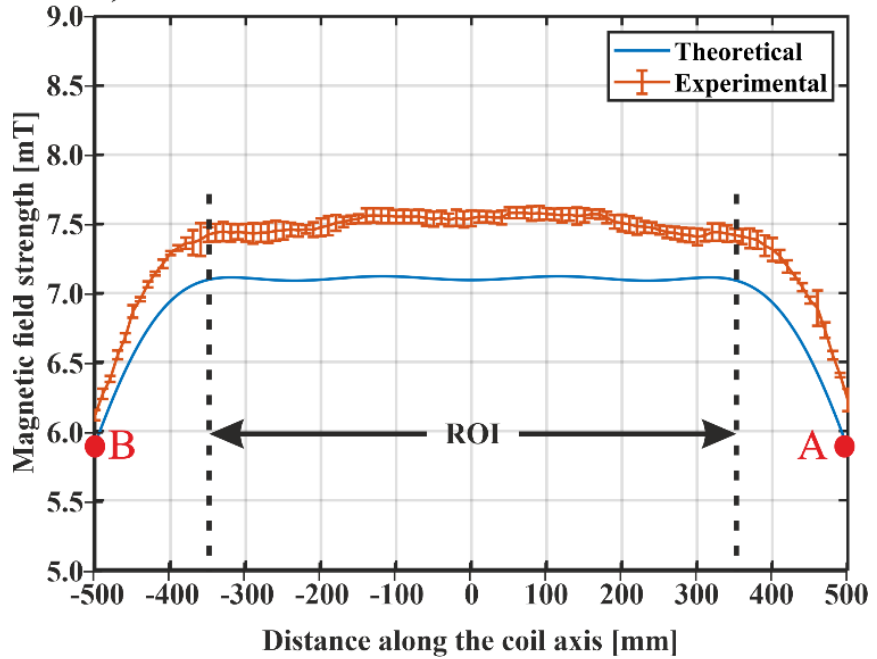

Figure 6. Theoretical calculations in $2 \mathrm{D}$ with magnetic field strength (in $\mathrm{mT}$ ) for 4-coil in (a) and comparison of magnetic field strength values with experimental results from A to B in (b). ROI is shown as a transparent rectangle in (a).

The theoretical results of 2-coil, 3-coil, and 4-coil systems and experimental results of the 4-coil system are summarized in Table 2 for the line profiles from A to B. It was noted that the 4-coil system provides higher homogeneity than the 2-coil and 3-coil systems within ROI, as shown in Table 2.

The measured magnetic fields along the coil radii (i.e. horizontally) were also compared with the simulated line profiles of the 4-coil system (Figure 1b) for I-element from $\mathrm{C}$ to D, II-element from $\mathrm{E}$ to $\mathrm{F}$, III-element from $\mathrm{G}$ to $\mathrm{H}$, and IVelement from $\mathrm{I}$ to $\mathrm{J}$ in Figure 7. Mean magnetic field strength values and standard deviations in ROI are given in Table 3. While the measured values were greater than the simulated values, the simulated and measured values were following a similar trend along the coil radius. As expected, the magnetic fields were higher at the coil edges. Nonetheless, field variations were very small and less than $1 \%$ at the points between $-100 \mathrm{~mm}$ and $100 \mathrm{~mm}$. Correlation coefficients between the simulated curves and measured magnetic fields were summarized in Table 4, including the p-values.
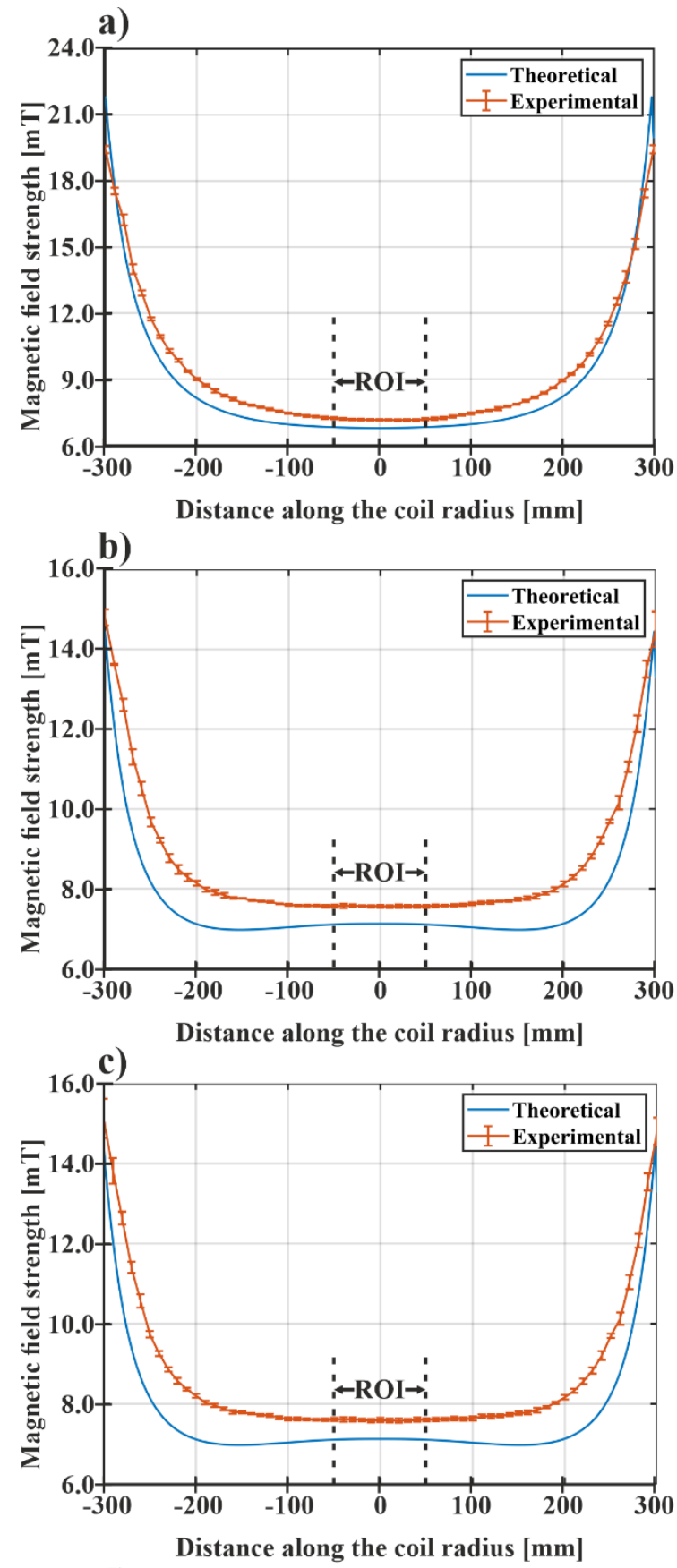

d)

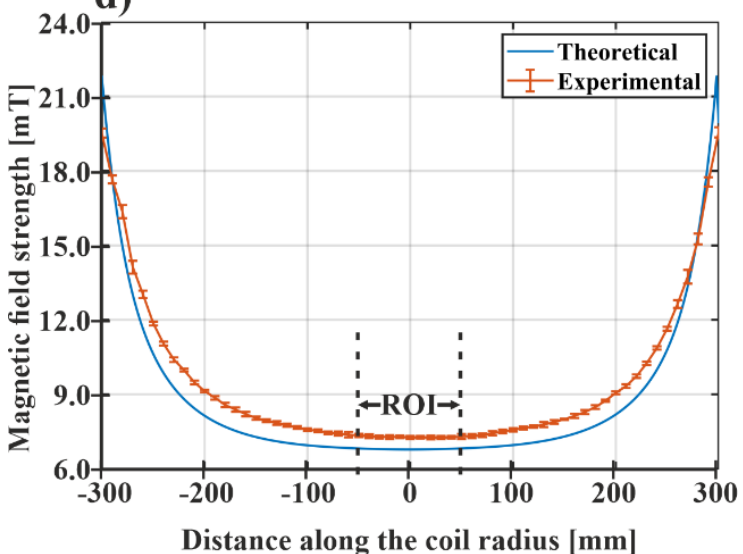

Figure 7. Comparison of theoretical calculations and experimental results from $\mathrm{C}$ to $\mathrm{D}(\mathrm{a}), \mathrm{E}$ to $\mathrm{F}(\mathrm{b}), \mathrm{G}$ to $\mathrm{H}$ (c), and I to $\mathrm{J}(\mathrm{d})$. 
TABLE III

MAGNETIC FIELD STRENGTH VALUES OF RADII GENERATED BY COIL SYSTEMS WITHIN THE ROI

\begin{tabular}{cccc}
\hline \hline & $\begin{array}{c}\text { MEAN MAGNETIC } \\
\text { FIELD STRENGTH } \\
(\mathrm{MT})\end{array}$ & $\begin{array}{c}\text { STANDARD } \\
\text { DEVIATION } \\
(\mathrm{MT})\end{array}$ & $\begin{array}{c}\text { STANDARD } \\
\text { DEVIATION } \\
(\mathrm{PPM})\end{array}$ \\
\hline C-D (I-ELEMENT) & 7.1722 & 0.3520 & 4907 \\
E-F (II-ELEMENT) & 7.5616 & 0.0592 & 783 \\
G-H (III-ELEMENT) & 7.5946 & 0.1214 & 1598 \\
I-J (IV-ELEMENT) & 7.2909 & 0.3802 & 5215 \\
\hline \hline
\end{tabular}

TABLE IV

CORRELATION COEFFICIENTS BETWEEN SIMULATED AND MEASURED VALUES

\begin{tabular}{ccc}
\hline \hline & CORRELATION & P-VALUE \\
\hline A-B & 0.9824 & $<0.001$ \\
C-D (I-ELEMENT) & 0.9922 & $<0.001$ \\
E-F (II-ELEMENT) & 0.9783 & $<0.001$ \\
G-H (III-ELEMENT) & 0.9810 & $<0.001$ \\
I-J (IV-ELEMENT) & 0.9923 & $<0.001$ \\
\hline \hline
\end{tabular}

\section{DISCUSSION}

A Helmholtz coil pair system forming of 4 coil elements was designed and optimized for the production of a uniform magnetic field that is potentially suitable for a low-field MRI or SEOP system. The coil windings, number of elements, and electric current were simulated to optimize the design and construction. Using an inexpensive copper wire and power supplies, the designed system generated a magnetic field of $7.5 \mathrm{mT}$ with a field homogeneity less than $1 \%$ over a selected ROI that was covered $700 \mathrm{~mm}$ vertically and $90 \mathrm{~mm}$ horizontally. Although the horizontal homogeneity analysis was performed over a length of $90 \mathrm{~mm}$, it can be extended up to $200 \mathrm{~mm}$ depending on the application.

The proposed system generated a magnetic field strength and uniformity that was comparable to the Helmholtz coil system reported by Mair et al. that could generate a field strength of $3.8 \mathrm{mT}$ and a field uniformity of $1000 \mathrm{ppm}$. However, the proposed 4-coil setup benefits a smaller coil diameter (i.e. diameter of $600 \mathrm{~mm}$ ) compared to the system designed by Mair et al. (i.e. diameter of $2000 \mathrm{~mm}$ ) [7].

Although an electric current of $19.5 \mathrm{~A}$ was used in this study due to the limiting power of the DC supply, the magnetic field strength greater than $7.5 \mathrm{mT}$ can be achieved with more powerful DC supplies. Using the aluminum frames with the proposed design would benefit from the heat dissipation for the use of larger electric currents. Considering the resistive heating, our system was stable at $58.9^{\circ} \mathrm{C}$ without using any additional chiller system. Potentially for doubling the produced magnetic field strength, the copper wire used in this system can handle an electric current of up to $40 \mathrm{~A}$ using a chiller system.

The difference of $\sim 5.6 \%$ in magnetic field strength between experimental and theoretical values may originate from the sensitivity of the gaussmeter or the amplifying effect of the coil spools/surrounding ferromagnetic materials, which are in agreement with the similar results in the literature [30, 31], showing the experimental magnetic field strength measurements can be higher than the simulated magnetic field. Although the difference was $5.6 \%$ in the amplitude, the Pearson's correlation of line profiles was above 0.98 with $\mathrm{p}<0.001$ suggesting a statistically reasonable correlation. Despite the understanding of the variations in the amplitude requires more work, the proposed simulations were sufficient for the optimization of homogeneity and field strength.

As an alternative to high-field MRI, novel developed techniques have demonstrated the feasibility of low-field MRI with reasonable image quality. Particularly hyperpolarized ${ }^{129} \mathrm{Xe}$ gas renewed the interest in open-access low-field MRI systems with a magnetic field strength in the order of a few $\mathrm{mT}$ [7]. While the image artifacts originating from magnetic field inhomogeneity were still a problem, the development of more homogeneous magnetic field systems is expected to address image artifact-related problems [32]. The low cost of installation and maintenance of low-field MRI systems further validates the use of this imaging technique as an alternative to high-field MRI. The proposed 4-coil system would be suitable for the use of SEOP and/or small animal low-field MR imaging systems. In the future, we will discuss the use of the proposed systems for low-field MR imaging applications and polarization of ${ }^{129} \mathrm{Xe}$ gas for SEOP systems using a more powerful current supply including a power amplifier and a chiller system.

\section{CONCLUSION}

This study involved the simulation and optimization of 4coil resistive electromagnet and construction to create a homogeneous magnetic field over a selected ROI. The system was constructed using a total copper wire length of $900 \mathrm{~m}$. The required electric current is supplied by a standard low-power DC supply.

The proposed system provided a homogeneous magnetic field strength of $7.5 \mathrm{mT}$ with experimental variations of approximately $0.75 \%$ within an ROI of $700 \mathrm{~mm}$ to $90 \mathrm{~mm}$. The maximum resulting resistive heating was found to be $58.9^{\circ} \mathrm{C}$ for an electric current of $19.5 \mathrm{~A}$ without using a chiller system.

\section{ACKNOWLEDGEMENT}

This work was supported by the Scientific and Technological Research Council of Turkey (TÜBİTAK), Grant No: $118 \mathrm{C} 189$.

\section{REFERENCES}

[1] J. Hatta, M. Miyamoto, Y. Adachi, J. Kawai, G. Uehara, \& H. Kado. "SQUID-Based Low Field MRI System for Small Animals". Ieee Transactions on Applied Superconductivity, 21(3), 526-529, 2011.

[2] A.E. Campbell-Washburn, R. Ramasawmy, M.C. Restivo, I. Bhattacharya, B. Basar, D.A. Herzka, M.S. Hansen, T. Rogers, W.P. Bandettini, D.R. McGuirt, C. Mancini, D. Grodzki, R. Schneider, W. Majeed, H. Bhat, H. Xue, J. Moss, A.A. Malayeri, E.C. Jones, A.P. Koretsky, P. Kellman, M.Y. Chen, R.J. Lederman, \& R.S. Balaban. "Opportunities in Interventional and Diagnostic Imaging by Using HighPerformance Low-Field-Strength MRI". Radiology, 293(2), 384-393, 2019.

[3] T. Tavernier, \& A. Cotten. "High- versus low-field MR imaging". Radiol Clin North Am, 43(4), 673-81, viii, 2005.

[4] W. Dominguez-Viqueira, J. Parra-Robles, M. Fox, W.B. Handler, B.A. Chronik, \& G.E. Santyr. "A variable field strength system for 
hyperpolarized noble gas MR imaging of rodent lungs". Concepts in Magnetic Resonance Part B-Magnetic Resonance Engineering, 33b(2), 124-137, 2008

[5] G.P. Wong, C.H. Tseng, V.R. Pomeroy, R.W. Mair, D.P. Hinton, D. Hoffmann, R.E. Stoner, F.W. Hersman, D.G. Cory, \& R.L. Walsworth "A system for low field imaging of laser-polarized noble gas". Journal of Magnetic Resonance, 141(2), 217-227, 1999.

[6] C.H. Tseng, G.P. Wong, V.R. Pomeroy, R.W. Mair, D.P. Hinton, D. Hoffmann, R.E. Stoner, F.W. Hersman, D.G. Cory, \& R.L. Walsworth. "Low-field MRI of laser polarized noble gas". Physical Review Letters, 81(17), 3785-3788, 1998.

[7] R.W. Mair, M.I. Hrovat, S. Patz, M.S. Rosen, I.C. Ruset, G.P. Topulos, L.L. Tsai, J.P. Butler, F.W. Hersman, \& R.L. Walsworth. "He-3 lung imaging in an open access, very-low-field human magnetic resonance imaging system". Magnetic Resonance in Medicine, 53(4), 745-749, 2005 .

[8] A.M. Coffey, K.V. Kovtunov, D.A. Barskiy, I.V. Koptyug, R.V. Shchepin, K.W. Waddell, P. He, K.A. Groome, Q.A. Best, F. Shi, B.M Goodson, \& E.Y. Chekmenev. "High-Resolution Low-Field Molecular Magnetic Resonance Imaging of Hyperpolarized Liquids". Analytical Chemistry, 86(18), 9042-9049, 2014.

[9] O. Doganay, T.N. Matin, A. Mcintyre, B. Burns, R.F. Schulte, F.V. Gleeson, \& D. Bulte. "Fast dynamic ventilation MRI of hyperpolarized Xe-129 using spiral imaging". Magnetic Resonance in Medicine, 79(5), 2597-2606, 2018.

[10] O. Doganay, T. Matin, M. Chen, M. Kim, A. McIntyre, D.R. McGowan, K.M. Bradley, T. Povey, \& F.V. Gleeson. "Time-series hyperpolarized xenon-129 MRI of lobar lung ventilation of COPD in comparison to V/Q-SPECT/CT and CT". European Radiology, 29(8), 4058-4067, 2019.

[11] Y. Zheng, G.D. Cates, W.A. Tobias, J.P. Mugler, \& G.W. Miller. "Verylow-field MRI of laser polarized xenon-129". Journal of Magnetic Resonance, 249, 108-117, 2014

[12] S. Patz, I. Muradian, M.I. Hrovat, I.C. Ruset, G. Topulos, S.D. Covrig, E. Frederick, H. Hatabu, F.W. Hersman, \& J.P. Butler. "Human pulmonary imaging and spectroscopy with hyperpolarized Xe-129 at 0.2T". Academic Radiology, 15(6), 713-727, 2008.

[13] I.C. Ruset, L.L. Tsai, R.W. Mair, S. Patz, M.I. Hrovat, M.S. Rosen, I. Muradian, J. Ng, G.P. Topulos, J.P. Butler, R.L. Walsworth, \& F.W Hersman. "A system for open-access He-3 human lung imaging at very low field". Concepts in Magnetic Resonance Part B-Magnetic Resonance Engineering, 29b(4), 210-221, 2006.

[14] A.M. Coffey, M.A. Feldman, R.V. Shchepin, D.A. Barskiy, M.L. Truong, W. Pham, \& E.Y. Chekmenev. "High-resolution hyperpolarized in vivo metabolic C-13 spectroscopy at low magnetic field $(48.7 \mathrm{mT})$ following murine tail-vein injection". Journal of Magnetic Resonance, 281, 246-252, 2017.

[15] G. Norquay, G.J. Collier, M. Rao, N.J. Stewart, \& J.M. Wild. "Xe-129$\mathrm{Rb}$ Spin-Exchange Optical Pumping with High Photon Efficiency". Physical Review Letters, 121(15), 2018.

[16] B. Driehuys, J. Pollaro, \& G.P. Cofer. "In vivo MRI using real-time production of hyperpolarized Xe-129". Magnetic Resonance in Medicine, 60(1), 14-20, 2008.

[17] P. Nikolaou, A.M. Coffey, L.L. Walkup, B.M. Gust, C.D. LaPierre, E. Koehnemann, M.J. Barlow, M.S. Rosen, B.M. Goodson, \& E.Y Chekmenev. "A 3D-Printed High Power Nuclear Spin Polarizer". Journal of the American Chemical Society, 136(4), 1636-1642, 2014.

[18] F.W. Hersman, I.C. Ruset, S. Ketel, I. Muradian, S.D. Covrig, J. Distelbrink, W. Porter, D. Watt, J. Ketel, J. Brackett, A. Hope, \& S. Patz. "Large production system for hyperpolarized Xe-129 for human lung imaging studies". Academic Radiology, 15(6), 683-692, 2008.

[19] C.Z. Cooley, J.P. Stockmann, B.D. Armstrong, M. Sarracanie, M.H Lev, M.S. Rosen, \& L.L. Wald. "Two-Dimensional Imaging in a Lightweight Portable MRI Scanner without Gradient Coils". Magnetic Resonance in Medicine, 73(2), 872-883, 2015.

[20] P.C. McDaniel, C.Z. Cooley, J.P. Stockmann, \& L.L. Wald. "The MR Cap: A single-sided MRI system designed for potential point-of-care limited field-of-view brain imaging". Magn Reson Med, 82(5), 19461960, 2019.

[21] T. O'Reilly, W.M. Teeuwisse, D. de Gans, K. Koolstra, \& A.G. Webb. "In vivo 3D brain and extremity MRI at $50 \mathrm{mT}$ using a permanent magnet Halbach array". Magn Reson Med, 85(1), 495-505, 2021.

[22] O. Doganay, M. Chen, T. Matin, M. Rigolli, J.A. Phillips, A. McIntyre, \& F.V. Gleeson. "Magnetic resonance imaging of the time course of hyperpolarized Xe-129 gas exchange in the human lungs and heart". European Radiology, 29(5), 2283-2292, 2019.
[23] P. Judeinstein, F. Ferdeghini, R. Oliveira-Silva, J.M. Zanotti, \& D. Sakellariou. "Low-field single-sided NMR for one-shot 1D-mapping: Application to membranes". J Magn Reson, 277, 25-29, 2017.

[24] M.C. Tourell, T.S. Ali, H.J. Hugo, C. Pyke, S. Yang, T. Lloyd, E.W. Thompson, \& K.I. Momot. "T(1) -based sensing of mammographic density using single-sided portable NMR". Magn Reson Med, 80(3), 1243-1251, 2018

[25] D. Izci. "Feasibility of Gold based Hall Devices for Biosensing Purposes". European Journal of Technique, 36-49, 2020.

[26] M. Adil, \& Z. Rakisheva. "Design and Simulation of Uniform Magnetic Field". Balkan Journal of Electrical and Computer Engineering, 6(4), 22-26, 2018

[27] D. İzci. "Constructing an Electronic Circuitry for Label-free Hall Biosensors". Balkan Journal of Electrical and Computer Engineering, 366-372, 2019.

[28] R.A. Schill. "General relation for the vector magnetic field of a circular current loop: A closer look". Ieee Transactions on Magnetics, 39(2), 961-967, 2003.

[29] J.E. García-Farieta, \& A.H. Márquez. "Exploring the magnetic field of Helmholtz and Maxwell coils: a computer-based approach exploiting the superposition principle". Revista Brasileira de Ensino de Física, 42, 2020.

[30] A.F. Restrepo, E. Franco, H. Cadavid, \& C.R. Pinedo. "A comparative study of the magnetic field homogeneity for circular, square and equilateral triangular Helmholtz coils". 2017 International Conference on Electrical, Electronics, Communication, Computer, and Optimization Techniques (Iceeccot), 13-20, 2017.

[31] S.R. Gyawali, \& N.E. Islam, "Design and construction of helmholtz coil for biomagnetic studies on soybean.", University of MissouriColumbia,: Columbia, Mo., 2008.

[32] M. Mullen, \& M. Garwood. "Contemporary approaches to high-field magnetic resonance imaging with large field inhomogeneity". Prog Nucl Magn Reson Spectrosc, 120-121, 95-108, 2020.

\section{BIOGRAPHIES}

Yenal Gökpek obtained his BSc. degree in the physics department from Ege University in 2014. He received his MSc in mathematical physics from the same university in 2017. He is currently enrolled in the Ph.D. program of Fundamental Oncology Department of the Institute of Health Sciences at Ege University. His research interests are hyperpolarized Xenon-129, finite element analysis, magnetic field coils, RF coils, NMR, MRI, and their medical applications.

Özgün Boray Yurdakoş obtained his BSc. degree in the electrical engineering department from Dumlupinar University in 2012. He received his MSc in nanotechnology in 2016 and his second MSc in electrical engineering in 2019 from Dokuz Eylul University. He is currently enrolled in the Ph.D. program of Fundamental Oncology Department of the Institute of Health Sciences at Ege University. His research interests are medical image analysis, MR sequence design, multi-dimensional signal processing, and segmentation methods for medical images.

Özkan Doğanay received his BSc. degree in Physics at Ege University in 2007. He completed his MSc in the Department of Biomedical Physics at Ryerson University in 2007 and his Ph.D. in the Department of Medical Biophysics from the University of Western Ontario in 2015, where he earned a national cancer-research-training award (CIHR in CaRTT). He went on to work as a post-doctoral researcher in the Department of Oncology at the University of Oxford in 2015. His research interests are developing functional imaging techniques for early detection and quantification of lung diseases, the development of specialized magnetic resonance imaging (MRI) methods for detection of functional (i.e. gas exchange) abnormalities in lungs associated with thoracic radiation treatment of cancer, and lung ventilation disorders including Chronic Obstructive Pulmonary Deceases (COPD) and asthma. He is currently an Assistant Prof at Ege University in the Institute of Health Sciences. He builds a new laboratory, named Functional Lung Imaging laboratories at Ege University Hospital Respiratory Diseases Center (EGESAM) and develops novel hyperpolarized Xenon-129 MR imaging techniques. 